\title{
The Role of Health Promoters in Raising Mothers of Under-Five Children Knowledge, Attitude and Practices Regarding Malaria
}

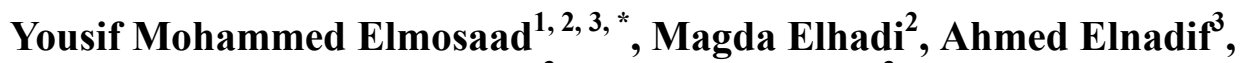 \\ Mustafa Mohammed Mustafa ${ }^{3}$, Ibrahim Alasqah ${ }^{3}$ \\ ${ }^{1}$ Primary Health Care Center, Faculty of Medicine, Gazira University, Wad Madni, Sudan \\ ${ }^{2}$ Department of Community Medicine, Faculty of Medicine, Gazira University, Wad Madni, Sudan \\ ${ }^{3}$ Department of Public Health, Faculty of Public Health and Health Informatics, Qassim University, Al-Bukairiyah, KSA
}

Email address:

Yousifm_34@hotmail.com (Y. M. Elmosaad)

*Corresponding author

\section{To cite this article:}

Yousif Mohammed Elmosaad, Magda Elhadi, Ahmed Elnadif, Mustafa Mohammed Mustafa, Ibrahim Alasqah. The Role of Health Promoters in Raising Mothers of Under-Five Children Knowledge, Attitude and Practices Regarding Malaria. Science Journal of Public Health. Vol. 5, No. 2, 2017, pp. 145-151. doi: 10.11648/j.sjph.20170502.22

Received: January 22, 2017; Accepted: February 6, 2017; Published: February 27, 2017

\begin{abstract}
A community-based intervention study was conducted in rural area of White Nile State, A total of 412 mothers of under-five children were selected randomly. To assess the role of health promoters in improving knowledge, developing positive attitudes and enhancing the practices of preventive activities against malaria among mothers of under-five children. Pre and Post data was collected using. A pre-coded, pre-tested, structured questionnaire. The data was analyzed through Statistical software Package for Social Sciences (SPSS) version 18. The results of the study show that; after intervention, the mean of mothers' knowledge of malaria increased significantly from 16.5 before intervention to 26 after intervention $(\mathrm{p}<0.001)$. Furthermore a positive attitude is developed that considerably increased from $75.2 \%$ pre-intervention to $99.3 \%$ post-intervention $(\mathrm{p}<0.05),(\mathrm{OR}=2.25)$. Moreover, the average mean practices score is increased significantly from 6.1 before intervention to 13.3 out of a maximum of 18 , after intervention $(\mathrm{p}<0.001)$. Based on our results a considerable increase was observed in the average means of mothers' knowledge, thus develop a positive attitude towards malaria and practice like use of preventives measured against malaria.
\end{abstract}

Keywords: Malaria, Mothers of Under-Five Children, Knowledge, Attitude, Practice, Health Promoters

\section{Introduction}

Malaria is a preventable disease; nevertheless, worldwide about 3.4 billion people are at risk of the malaria and around $40 \%$ of them live in the poorest countries [1]. The vast majority of estimated morbidity (80\%) and mortality (91\%) occur in sub-Saharan Africa and the mortality is more common $(86 \%)$ in children $<5$ years of age [2]. Many children who survive an episode of severe malaria suffer permanently from learning impairments or brain damage [3] Malaria is a major public health problem in Sudan; More than $75 \%$ of the population is at risk for contracting malaria infection [4]. Despite decades of malaria control efforts, malaria still remains a major cause of morbidity and mortality in Sudan. The World Malaria Report (2015) shows that the estimated malaria incidence in Sudan was around 1000 cases per 100,000 population annually with a case fatality rate of about 6 deaths per 100,000 population [5].

The strategic approaches adopted by Sudan follow largely those recommended by WHO. These include the distribution of artemisinin-based combination therapy treatments, rapid diagnostic tests and long-lasting insecticide treated nets along with the introduction of the home-based management of malaria strategy to reduce the level of malaria infection and consequent death [5].

The increase in the prevalence of malaria is due to both behavioural and non-behavioural factors. The focus on 
community-directed interventions was driven by the large theoretical and empirical literature highlighting the importance of community involvement in the delivery of preventive health measures against malaria [6]. The past improvements appear in cases where communities actively and consciously participated in decision-making [7].

The behavioral factors related to some knowledge, attitude and practices, which promoted healthy behaviour, encouraged people at risk of malaria to use effective treatment, control and prevention activities against malaria promptly and adequately. However understanding of both behavioral and non-behavioral factors, is an important step to design appropriate interventions for prevention and control of malaria. All these evidences encourage the researchers to assess the role of health promoters in improving knowledge, developing positive attitudes and enhancing the practices of preventive activities among mothers of under-five children.

\section{Materials and Methods}

\subsection{Study Design}

A community-based intervention study was conducted in rural area of Kosti Locality- White Nile State, for one year starting from January 2014 and ending in January 2015 among mothers of under-five children, with objectives to assess the role of health promoters in raising KAP among the mothers regarding malaria.

\subsection{Study Area}

White Nile State lies in the South of North Sudan is an agricultural area this, makes the State susceptible to malaria transmission throughout the year. Primary malaria control and prevention activities are undertaken by State Ministry of Health, the National Malaria Control Programme (NMCP) along with non-Governmental organization (NGOs). Kosti locality is one of White Nile state localities.

\subsection{Study Population}

The study population included all the mothers of underfive children who were living in rural area (villages) of Kosti locality. A total number of 1720 mothers of under-five children distributed in 6 Kosti villages were enlisted,

\subsection{Sample Size}

The study sample was determined by using the following formula (Israel, 1992) and was found to be 412 mothers with children under-five years: $Z=$ Corresponding value to $95 \%$ confidence limits $=1.96, \mathrm{P}=$ general knowledge on malaria (0.45), $\mathrm{Q}=1-\mathrm{P}=(0.55), \mathrm{D}=$ Desired margin of error (absolute precision) $=0.05$.

\subsubsection{Sample Selection and Distribution}

Out of a total of 163 villages in Kosti locality, 6 villages were selected randomly and were used for this study. The selected villages located in North West region they were assessed two times during study period: pre-survey and post- survey, in order to select the mothers from the list of mothers made by the researchers prior to baseline survey systematic random sample was used, and so one mother was selected from each four mothers in list.

\subsubsection{Phases of the Study}

The study included the three phases namely:

Pre-assessment phase: In this phase, baseline data was collected using. A pre-coded, pre-tested, structured questionnaire that included socio - demographic characteristics of households and KAP related to malaria.

Intervention phase:

In the first steps health promotion teams in study villages were formed. Health promotion teams in study villages includes Women group leaders, female teachers and female volunteers who participated in the implementation and monitoring of the health education activities in their villages. Subsequently, training workshop was conducted for health promotion teams to create knowledge regarding malaria. The participants returned to their villages to carry out the health education activities. Each health promotion team member at the village level was responsible for 10 mothers of under-five children. And each health promotion team was supervised by a co-ordinator.

In the second step, baseline survey started and continued for a period of two week. At the end of the survey, all hard copies of questionnaires were submitted to the village coordinators and the researcher for daily review, and corrections were suggested wherever necessary.

Health education activities were carried out in various ways such as Health education sessions to disseminate the knowledge regarding malaria protective measures, early diagnosis and treatment through village health promotion teams through house to house visits. Training session to all mothers of under-five children. Sustained Massive Advertising was done in order to reach the desired behavioural outcomes and was conducted through distribution of health education materials in public places repeatedly throughout intervention period. Community Mobilization was done through the use of mothers' group meetings, home visits and partnership meetings to sensitize mothers. Administrative Mobilization: This involved meetings and discussions with the locality staff public health staff, who supported the health education activities and were responsible for mobilizing the village health promotion teams.

Post-evaluation: In this phase the tool that was used for data collection in pre-assessment were used in study villages before and after intervention period.

\subsection{Methods of Data Collection}

Data was collected through use of a pre-coded, pre-tested, structured questionnaire about KAP related to malaria from mothers, the data in all phases of the study was collected by (6) interviewers who were chosen and trained to conduct face-to-face interviews. 


\subsection{Data and Statistical Analysis}

The data was edited before, during and after leaving the respondents. The researcher checked for all the parameters involved in data analysis. A composite variable was generated to summarize overall mothers' knowledge about malaria and was calculated by adding up the score for each of all questions and the total score was 38 maximum. One point was given for correct answer, zero point was given for an incorrect answer and one point was subtracted from any incorrect answer for question with multiple answers. However the score value were converted to three classes [(Poor Knowledge (1-12), Moderate Knowledge (13-24) and Good Knowledge $(>25)]$.

The mothers answered (7) questions to assess their attitudes towards malaria. The response to the questions was in the form of Yes or No and a positive attitude with a response "yes" was given two point and a Negative attitude with a response "No" was given zero. An overall score about attitude towards malaria was calculated by adding up the score for each of all questions and the total score was 14 maximum. And then the mean of scores was divided into two groups, that is negative attitude $(<1)$ and positive attitude $(>1)$.

An overall score of practices of malaria prevention was calculated by adding up the score for each of all (13) questions and the total score was 18 maximum. This was classified into three categories (Poor practice (1-6), Fair practice (7-12) and Good practice (13-18).

In order to meet the study objectives, the data obtained from the research tool was analyzed. Depending on the nature of the variables, descriptive statistics were used to tabulate the data, and inferential statistics was used to examine association between categorical variables. Odds Ratio and Eta Square $\left(Л^{2}\right)$ were calculated to determine effect size of independent variable on dependent variable.

Since the data was normally distributed (Normality test $\mathrm{p}>$ (0.05), One way ANOVA and Independent sample T- test were done to explain the differences in health education activities outcome (KAP scores) by socio-demographic characteristics. Regression analysis was used to predict the effect of mothers' knowledge on their attitude and practices of preventive measures against malaria. The tests were carried out at $95 \%$ confidence interval, p-values less than 0.05 were considered significant, and Odds ratio (OR) with $95 \%$ confidence interval was used to assess the presence and degree of association between dependent and independent variables. The data was analyzed through Statistical software Package for Social Sciences (SPSS) version 18.

\section{Results}

Table 1. Distribution of the household by occupation, type of house education level, monthly income, age group, family size and number of under-five children.

\begin{tabular}{ll}
\hline Household Characteristics & Intervention villages (N=412) \\
\hline Occupation of the husband: $(\mathbf{N o .} / \%)$ & $35(8.5)$ \\
\hline Employee & $30(7.3)$ \\
Merchant & $85(20.6)$ \\
Farmer & $243(59.0)$ \\
Self-employee & $19(4.6)$ \\
Others & \\
Education level $(\mathrm{No} . / \%)$ & $117(28.4)$ \\
Informal education & $295(71.6)$ \\
Formal education & $492.2 \pm 547.1$ \\
Monthly income $(\mathrm{M} \pm \mathrm{SD}) \#$ & $29.3 \pm 6.7$ \\
Age group of mothers $(\mathrm{M} \pm \mathrm{SD}) \#$ & $5.3 \pm 2.1$ \\
Family size $(\mathrm{M} \pm \mathrm{SD})$ & $1.6 \pm 0.7$ \\
Number of children $<5$ years $(\mathrm{M} \pm \mathrm{SD})$ & 0.529 \\
\hline
\end{tabular}

** Percent calculated of total sample for each category

\pm Plus-minus values are means \pm standard deviations (SD).

The majority of study subjects had formal education $(71.6 \%)$, and the mean household monthly income was $492.2 \pm 547.1$ Sudan Pound. Also mothers in reproductive age (15 to 44 years), were $97.1 \%$ (Table 1 ).

\subsection{Overall Malaria Knowledge and Practice Score}

A total score about overall Knowledge about malaria was calculated by adding up the score for each of all twenty questions and the total score was thirty eight maximum. A total score about overall practice of malaria preventive was calculated by adding up the score for each of all 13 questions and the total score was 18 maximum

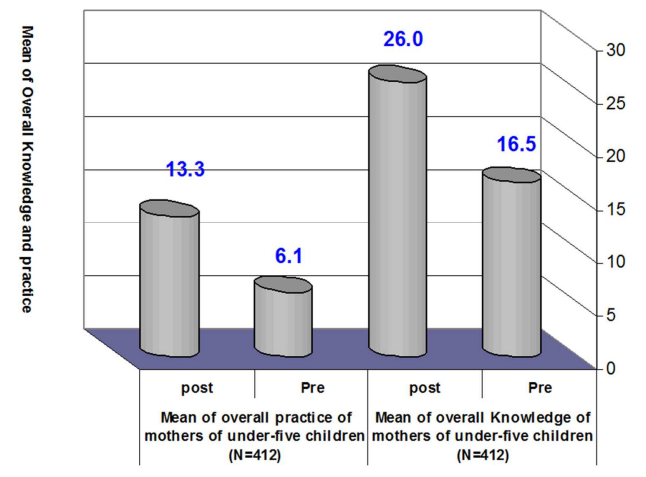

Figure 1. Pre- and post-intervention Levels of overall practice and Knowledge of mothers with children $<5$ years, about malaria. 
The results in the above graph (Figure 1) showed the average means of mothers' knowledge about malaria. After intervention, the mean knowledge increased significantly from 16.5 before intervention to 26 after intervention $(\mathrm{p}<0.001)$.
Also shows that the average means of mothers' practices regarding malaria prevention measures. After intervention, the mean practice score increased significantly from 6.1 before intervention to 13.3 after intervention $(p<0.001),\left(\pi^{2}=0.79\right)$.

Table 2. Pre- and post-intervention levels of overall KAP outcome of mothers of under-five children, about malaria.

\begin{tabular}{|c|c|c|c|c|c|c|}
\hline \multirow{2}{*}{ Variables } & \multirow{2}{*}{ Response level } & \multicolumn{2}{|c|}{ Mothers KAP out come $(\mathrm{N}=412)$} & \multirow{2}{*}{$\chi^{2}$} & \multirow{2}{*}{ p-value } & \multirow{2}{*}{$\begin{array}{l}\text { OR / CI }[95 \% \\
\text { confidence interval }]\end{array}$} \\
\hline & & Pre & post & & & \\
\hline \multirow{3}{*}{$\begin{array}{l}\text { Overall Knowledge about } \\
\text { malaria }\end{array}$} & Poor Knowledge & $100(12.1)$ & $1(0.1)$ & \multirow{3}{*}{354.7} & \multirow{3}{*}{$\begin{array}{l}0.001 \\
\pi^{2}=0.64\end{array}$} & \multirow{3}{*}{-} \\
\hline & Moderate Knowledge & $281(34.1)$ & $129(15.7)$ & & & \\
\hline & Good Knowledge & $31(3.8)$ & $282(34.2)$ & & & \\
\hline \multirow{2}{*}{ Attitude towards malaria } & Negative attitude & $102(24.8)$ & $3(0.7)$ & \multirow{2}{*}{106.9} & \multirow{2}{*}{$\begin{array}{l}0.001 \\
\pi^{2}=0.36\end{array}$} & \multirow{2}{*}{$\begin{array}{l}{[\mathrm{OR}=2.25,} \\
\mathrm{CI}(2.05-2.46)]\end{array}$} \\
\hline & Positive attitude & $310(75.2)$ & 409 (99.3) & & & \\
\hline \multirow{3}{*}{$\begin{array}{l}\text { Practice of protective } \\
\text { measures against malaria }\end{array}$} & Poor practice & $267(32.4)$ & $0(0.0)$ & \multirow{3}{*}{523} & \multirow{3}{*}{$\begin{array}{l}0.001 \\
\pi^{2}=0.79\end{array}$} & \multirow{3}{*}{-} \\
\hline & Fair practice & $138(16.7)$ & $135(16.4)$ & & & \\
\hline & Good practice & $7(0.8)$ & $277(33.6)$ & & & \\
\hline
\end{tabular}

The results in the above table 2 showed that $12.1 \%$ of mothers had poor knowledge about malaria which significantly reduced to $0.1 \%$, this was found to be statistically significant, $(\mathrm{p}<0.05)$. This signifies that level of knowledge increased by $64 \%$ which might be due to health education activities $\left(\pi^{2}=0.64\right)$.

With regard to the attitude of mothers of under-five children, towards malaria. The results showed $75.2 \%$ of mothers of under-five, had a positive attitude towards malaria, which significantly increased to $99.3 \%$ after the intervention $(\mathrm{p}<0.05)$. However $24.8 \%$ of them had a negative attitude towards malaria, which significantly reduced to a mere $0.7 \%$ after the intervention. Mothers after the intervention developed a positive attitude towards malaria more than two times higher than baseline data $(\mathrm{OR}=2.25)$.

Related to the Overall score of practice of malaria prevention. The above table 2 showed that $0.8 \%$ of mothers with children under 5 years, had good preventive practices against malaria that significantly increased to $33.6 \%$ after the intervention $(\mathrm{p}<0.05)$. While $32.4 \%$ of them had poor preventive practices, that significantly reduced to zero after intervention.

\subsection{Differences in Impact Health Education Outcome (KAP Scores) by Socio-Demographic Characteristics}

Table 3. Health education outcome (KAP scores) by age, education, occupation and family size, number of under-five children (N=412).

\begin{tabular}{|c|c|c|c|c|c|c|c|c|}
\hline \multirow[t]{2}{*}{ Socio - demographic } & \multicolumn{2}{|c|}{$\begin{array}{l}\text { Knowledge score } \\
\text { mean (sd) }\end{array}$} & \multicolumn{2}{|c|}{$\begin{array}{l}\text { Attitude score } \\
\text { mean (sd) }\end{array}$} & \multicolumn{2}{|c|}{$\begin{array}{l}\text { Practice score } \\
\text { mean (sd) }\end{array}$} & \multicolumn{2}{|c|}{$\begin{array}{l}\text { Overall KAP score } \\
\text { mean (sd) }\end{array}$} \\
\hline & Pre & Post & Pre & Post & Pre & Post & Pre & Post \\
\hline Education level: & & $*$ & & $*$ & & $*$ & & $*$ \\
\hline - Formal education & $16.8(5.2)$ & $26.4(3.5)$ & $11.3(1.1)$ & $12.8(0.8)$ & $6.3(2.5)$ & $13.5(1.8)$ & $34.5(6.7)$ & $52.8(4.1)$ \\
\hline - Informal & $16.3(5.8)$ & $24.8(3.4)$ & $11.3(1.2)$ & $12.8(0.6)$ & $6.1(2.4)$ & $12.6(2.0)$ & $33.7(7.2)$ & $50.2(4.7)$ \\
\hline Monthly household income: & & $*$ & & & & & $*$ & $*$ \\
\hline $100-400$ & $16.0(5.7)$ & $25.7(3.5)$ & $5.9(2.3)$ & $12.8(0.69)$ & $11.2(1.1)$ & $13.2(1.9)$ & $33.1(7.1)$ & $51.7(4.3)$ \\
\hline $401-800$ & $17.2(5.5)$ & $26.6(3.3)$ & $6.4(2.5)$ & $12.8(0.46)$ & $11.4(1.2)$ & $13.2(1.9)$ & $35.0(6.9)$ & $52.7(3.9)$ \\
\hline$>801$ & $16.8(5.4)$ & $27(3.5)$ & $6.5(2.2)$ & $12.8(0.64)$ & $11.5(1.1)$ & $13.7(1.8)$ & $34.8(7.0)$ & $53.6(4.2)$ \\
\hline \multicolumn{9}{|l|}{ Age in years } \\
\hline $15-29$ & $16.4(5.3)$ & $26.0(3.6)$ & $11.3(1.2)$ & $12.7(0.71)$ & $6.1(2.3)$ & $13.1(1.9)$ & $33.8(6.5)$ & $51.9(4.6)$ \\
\hline $30-44$ & $16.6(5.9)$ & $25.9(3.5)$ & $11.3(1.1)$ & $12.9(0.59)$ & $6.2(2.4)$ & $13.5(1.8)$ & $34.1(7.6)$ & $52.2(4.2)$ \\
\hline$>45$ years & $17.5(6.4)$ & $26.8(2.2)$ & $11.7(1.2)$ & $12.6(0.65)$ & $5.3(1.5)$ & $13.3(2.3)$ & $34.5(7.5)$ & $52.7(4.0)$ \\
\hline Household occupation: & & $*$ & & & & & & $*$ \\
\hline Officer & $16.8(6.4)$ & $27.1(3.8)$ & $11.4(1.2)$ & $12.9(0.49)$ & $6.1(1.9)$ & $13.5(1.7)$ & $34.3(7.9)$ & $53.4(4.3)$ \\
\hline Merchant & $16.9(5.3)$ & $26.2(3.4)$ & $11.4(1.3)$ & $12.8(0.61)$ & $5.9(2.4)$ & $13.4(1.5)$ & $34.3(6.7)$ & $52.4(3.9)$ \\
\hline Farmer & $15.8(5.7)$ & $24.9(3.9)$ & $11.2(1.2)$ & $12.8(0.78)$ & $6.1(2.6)$ & $12.9(2.0)$ & $33.1(7.6)$ & $50.6(5.0)$ \\
\hline Self-employee & $16.7(5.5)$ & $26.2(3.3)$ & $11.3(1.1)$ & $12.8(0.62)$ & $6.2(2.4)$ & $13.3(1.9)$ & $34.3(6.9)$ & $52.3(4.0)$ \\
\hline Others jobs & $15.3(5.4)$ & $25.4(4.5)$ & $11.5(0.90)$ & $12.9(0.77)$ & $5.6(1.9)$ & $13.8(1.8)$ & $32.4(5.9)$ & $52.2(5.8)$ \\
\hline Family size: & & & & & & & & $*$ \\
\hline $1-4$ & $16.4(5.8)$ & $25.7(3.7)$ & $11.2(1.2)$ & $12.7(0.70)$ & $6.3(2.4)$ & $13.0(1.9)$ & $33.9(7.2)$ & $51.5(4.5)$ \\
\hline $5-8$ & $16.4(5.5)$ & $26.0(3.5)$ & $11.4(1.1)$ & $12.8(0.63)$ & $5.9(2.2)$ & $13.4(1.8)$ & $33.8(6.9)$ & $52.2(4.3)$ \\
\hline$>9$ & $17.8(5.4)$ & $26.7(3.0)$ & $11.4(1.2)$ & $13.1(0.57)$ & $6.7(2.9)$ & $13.6(1.7)$ & $35.9(7.1)$ & $53.4(3.7)$ \\
\hline \multicolumn{9}{|l|}{ No. of children $<5$ years: } \\
\hline $1-2$ & $16.5(5.6)$ & $26.0(3.6)$ & $11.3(1.2)$ & $12.8(0.6)$ & $6.2(2.4)$ & $13.2(1.8)$ & $34.0(7.1)$ & $52.0(4.4)$ \\
\hline$>3$ & $16.5(5.7)$ & $25.9(3.6)$ & $11.2(1.0)$ & $12.8(0.8)$ & $5.8(2.4)$ & $13.8(2.1)$ & $33.5(7.1)$ & $52.4(4.6)$ \\
\hline
\end{tabular}

* Statistically significant with the category differences, $\mathrm{p} \leq 0.05$

Table 3 review the respondents' KAP level by socio-demographic characteristics. Mothers having formal education in study 
area were associated with higher scores of desired knowledge, attitudes and practices $(\mathrm{p}<0.05)$.

Overall KAP scores were positively associated with monthly household income, occupation and family size $(\mathrm{p}<0.05)$. While, KAP scores were not associated with age groups and number of children less than 5 years, $(p>0.05)$.

\subsection{Comparing Practices and Knowledge About Malaria}

Table 4. Association between Malaria Practices and Malaria Knowledge (chi square test).

\begin{tabular}{|c|c|c|c|c|c|c|c|c|}
\hline \multirow{2}{*}{ Knowledge } & \multirow[b]{2}{*}{ Practices } & \multicolumn{2}{|c|}{ Poor Knowledge } & \multicolumn{2}{|c|}{ Good Knowledge } & \multirow{2}{*}{$\left(\chi^{2}\right)$} & \multirow{2}{*}{ OR / 95\% Confidence Interval } & \multirow{2}{*}{ P-value } \\
\hline & & No. & $\%$ & No. & $\%$ & & & \\
\hline Poor practice & & 6 & 1.5 & 129 & 31.3 & \multirow{3}{*}{4.80} & \multirow{3}{*}{$\mathrm{OR}=4.25 \mathrm{CI}=(1.05-17.3)$} & \multirow{3}{*}{0.037} \\
\hline Good practice & & 3 & 0.7 & 274 & 66.5 & & & \\
\hline Total & & 9 & 2.2 & 403 & 97.8 & & & \\
\hline
\end{tabular}

Table 4 showed that comparing mothers practice scores to malaria knowledge scores using the Chi-Square test indicated that there was a statistically significant association between mothers' knowledge about malaria and their practices towards malaria $(\mathrm{p}=0.037)[\mathrm{OR}=4.25 \mathrm{CI}=(1.05-17.3)]$.

\subsection{Comparing Malaria Practices to Attitudes}

Table 5. Association between Malaria Practices and Malaria Attitudes.

\begin{tabular}{llllll}
\hline Attitudes & \multicolumn{2}{l}{ Negative attitude } & \multicolumn{3}{c}{ Positive attitude } \\
\cline { 2 - 5 } & Practices & No. & \% & No. & \% \\
\hline Poor practice & 3 & 0.7 & 132 & 32.0 \\
Good practice & 0 & 0 & 277 & 67.2 & 0.035 \\
Total & 3 & 0.7 & 409 & 99.3 \\
\hline
\end{tabular}

* 2 cells $(50 \%)$ have expected count less than 5 . Hence Fisher's exact test was used.

Table 5 showed that comparing malaria practice scores to malaria attitude scores using the Fisher's exact test confirmed that there was a statistically significant association between mothers' attitudes and their practices against malaria (Fisher's exact $=0.034655$ ).

\section{Relationship Between Level of Knowledge and Practices of Preventive Measures of Malaria}

Table 6. Relationship between level of knowledge, attitudes towards malaria and practices of preventive measures of malaria by mothers of under-five children after intervention.

\begin{tabular}{llllllll}
\hline \multirow{2}{*}{ Variables } & \multicolumn{7}{c}{ After Intervention $(\mathbf{N}=412)$} \\
\cline { 2 - 8 } & Mean & SD & Beta & T & F & $\mathbf{R}^{\mathbf{2}}$ & Sign \\
\hline Attitude & 12.1 & 6.7 & 0.64 & 23.6 & 555.9 & 0.40 & 0.001 \\
Practice & 9.7 & 4.2 & 0.67 & 25.8 & 669.9 & 0.45 & 0.001 \\
\hline
\end{tabular}

*Independent variable: Overall level of Knowledge

*Dependent variable: Overall level of practice/attitude

\#Overall level of mothers Knowledge after intervention $=21.2 \pm 6.7$

\#Overall level of attitude of mothers after intervention $=(12.1 \pm 1.2)$

\#Overall level of practice of mothers after intervention $=(9.7 \pm 4.2)$

The above table 6 depicts the relationship of knowledge with attitudes and practices of mothers in study area. The knowledge among the mothers, as a result of health education activities, had a positive impact on the attitudes and practices of preventive measures against malaria. This is signified by a linear regression for knowledge and attitudes, and knowledge and practices showing that Beta was 0.64 and 0.67 and $\mathrm{R}^{2}$ was 0.40 and 0.45 respectively. Both were found to be statistically significant $(\mathrm{p}<0.05)$. This explains that health education had a positive impact on the attitudes of mothers towards preventive measure against malaria

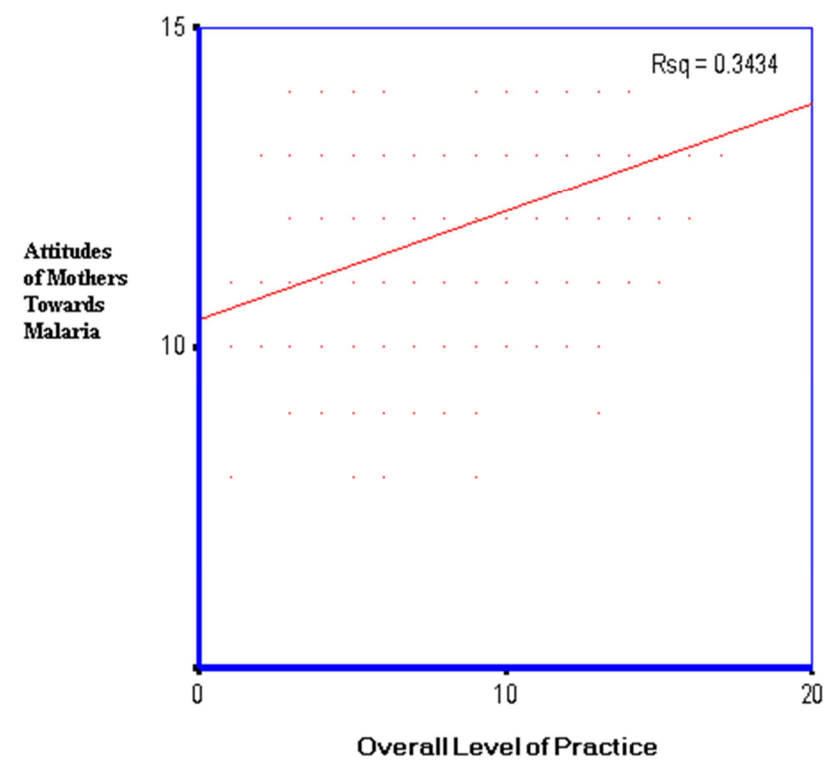

Figure 2. The relationship of attitudes with practices of mothers after intervention

Beta $=0.59, \mathrm{R}=0.59, \mathrm{~T}=20.7, \mathrm{~F}=429.9, \mathrm{P}=0.001$;

*Independent variable: Overall level of attitude;*Dependent variable: Overall level of practice;

The above Figure. 2 depicts the relationship of attitudes with practices of mothers after intervention. The attitudes 
among the mothers after intervention, as a result of health education activities had a positive impact on the practices of preventive measures against malaria. This is explained by a linear regression for attitudes and practices showing that Beta was 0.59 and $\mathrm{R}^{2}$ was 0.34 . This was found to be statistically significant $(\mathrm{p}<0.05)$.

\section{Discussion}

Malaria is the leading cause of morbidity and mortality in Sudan [4]. The entire population of Sudan including White Nile state, are at risk of contracting malaria especially people living on villages near river banks - due to increased mosquito density. In this study, comprehensive health education activities were conducted in the intervention villages through health promotion teams on the basis of the situation analysis findings.

This study established the effectiveness of the health education activities, administered to mothers who were having children less than 5 years and were living in rural Kosti locality area and this resulted in improvement of KAP regarding malaria among mothers in addition recognized relationships between Knowledge, Attitude and Practices among mothers, in relation to malaria prevention, as shown in the following discussion.

The results showed that the overall mothers' knowledge about malaria prevention and control, the results showed that $12.1 \%$ of mothers had poor knowledge of the same which significantly reduced to $0.1 \%$, while spontaneously the average means of mothers' knowledge of malaria increased by $64 \%(p<0.05),\left(\pi^{2}=0.64\right)$. This finding was similar to a study conducted by Adebayo et al., in 2015 who found that the general knowledge about prevention and control of malaria was good [8]. Moreover, Rhee et al., in 2005 found significant increase in knowledge levels about malaria prevention and control for each individual pre- and post educational intervention $(\mathrm{p}<0.001)$ [9]. While in contrast, a study conducted in Uganda by Mwanje in 2013 who found that $20 \%$ of respondents had poor knowledge about malaria prevention and control [10]. However, the results of this study were lesser than that of the study which was done in Cameroon by Nwana in 2011 who found that $56.12 \%$ of the respondents had good knowledge of malaria prevention and control after intervention [11].

Concerning attitudes of mothers with children less than 5 years towards malaria, the results showed that mothers after the intervention developed a positive attitude which considerably increased from $75.2 \%$ pre-intervention to $99.3 \%$ post-intervention $(\mathrm{p}<0.05),(\mathrm{OR}=2.25)$. This is in contrast with Onwujekwe et al., who in 2005 found that some respondents had poor attitudes about the use of personal protective measure [6].

With regards to the practice of preventive measures by mothers with children less than 5 years, the results showed the implementation of health education activities lead to a considerable improve in the level of practice of preventive measures, the average mean practices score increased significantly from 6.1 before intervention to 13.3 out of a maximum of 18 , after intervention $(\mathrm{p}<0.001)$. This result is similar to Nahla et al., who in 2009, found that high knowledge was the only predictor of high mean practice score [12]. While our result was lower than study conducted by Envuladu et al., in 2012 who found that the health education intervention increased practice of sleeping under the nets considerably $\left(\mathrm{X}^{2}=82.01, \mathrm{p}<0.001\right)$, [13].

With regard to inter-relationship between level of knowledge, attitudes and practices of preventive measures of malaria, it was found that the knowledge among the mothers, as a result of health education activities had a positive impact on the attitudes and practices of preventive measures against malaria (linear regression - Beta was 0.64 and 0.67 and $\mathrm{R}^{2}$ was 0.40 and 0.45 respectively).

Also in this study, overall score of pre-intervention knowledge was low at $43.4 \%$, the score of attitude and practices related to malaria was $24.8 \%$, and $46.9 \%$ respectively. After intervention, these scores increased to $56.6 \%, 99.3 \%$ and $79.0 \%$ respectively. This is in agreement with the findings of a study done by Nahla et al. in 2009, [12].

Related to the differences in health education activates outcome (KAP scores), among mothers, by sociodemographic characteristics, the result showed that overall KAP scores were positively associated with monthly household income, occupation and family size $(p<0.05)$. Also mothers with under five years children, having formal education were associated with higher scores of desired knowledge, attitudes and practices $(\mathrm{p}<0.05)$. This finding was similar to the Yoder, who in 2008 reported that Armenian women having higher education level were associated with higher scores of desired knowledge attitudes and practices $(\mathrm{p}<0.05)$ [14].

\section{Conclusion}

It is concluded that mothers having formal education were more likely to have good knowledge, positive attitudes and fair practices in relation to malaria prevention compared to mothers who did not have formal education. Also it was seen that mothers having formal education were more receptive to health education programs conducted by health promotion teams.

\section{Recommendation}

There is a need to concentrate on health education to increase awareness, developing a positive perception towards malaria and improving mothers' practices regarding malaria prevention.

\section{References}

[1] WHO., (2014). World malaria report. Geneva: World Health Organization.

[2] WHO., (2012). World malaria report. Geneva: World Health Organization. 
[3] WHO., (2013). World Malaria Report. Geneva: World Health Organization [Available at:

http://www.who.int/malaria/publications/world_malaria_repor t_2013/en/]UNICEF, 2005].

[4] National Malaria Control Programme (2013). Malaria indicator survey. The Republic of Sudan: Republic of Sudan. Federal Ministry of Health.

[5] WHO., (2015). World malaria report. Geneva: World Health Organization.

[6] Onwujekwe O, Uzochukwu O. B, Ezuumah N, and Shu E, (2005). Increasing Coverage of Insecticide Treated Nets in Rural Nigeria Implications of Consumer Knowledge, Preferences and Expenditures for Malaria Preventions. Malaria J.

[7] Moses K., Peace H., Albert E., Stella A., Catherine M., (2009). Monitoring ivermectin distributors involved in integrated health care services through community-directed interventions - a comparison of Cameroon and Uganda experiences over a period of three years. Journal of Tropical Medicine and International Health.

[8] Adebayo AM, Akinyemi OO, Cadmus EO., (2015). Knowledge of malaria prevention among pregnant women and female caregivers of under-five children in rural southwest Nigeria.
[9] Rhee M, Sissoko M, Perry S, McFarland W, Parsonnet J, Doumbo O., (2005). Use of insecticide-treated nets (ITNs) following a malaria education intervention in Piron, Mali: a control trial with systematic allocation of households Malar J.

[10] Mwanje LF., (2013). Knowledge, attitudes and practices on malaria prevention and control in Uganda, [Available at: http://www.musphcdc.ac.ug].

[11] Nwana TB., (2011). Knowledge and utilization of insecticide treated nets to prevent malaria in cameroon (a case of the mount fako region). Public Health Management: Ritsumeikan Asia Pacific University.

[12] Ibrahim NK, Al-Bar A, Kordey M, Al-Fakeeh A., (2009). Knowledge, attitudes, and practices relating to dengue fever among females in Jeddah high schools. J Infect Public Health.

[13] Envuladu EA, Banwat ME, Lar LA, Miner CA, Agbo HA, Zoakah AI., (2012). Effect of community based intervention on awareness and utilization of the long lastinig insecticidal nets in a rural area of Barkin ladi LGA Plateau state Nigeria. E3 Journal of Medical Research.

[14] Richard A. Y., (2008). knowledge, attitudes, and practices survey, baseline evaluation in aragatsotn, armavir, and ararat marzes, the United States Agency for International Development (USAID). 